\title{
Structure of the Optimal Management System for Raw Materials, Fuel and Energy Resources in Blast-furnace Production
}

Nikolay Spirin, Oleg Onorin, Ivan Gurin, Vladislav Lavrov, and Kirill Shchipanov

Ural Federal University (UrFU), Yekaterinburg, Russia

\section{Abstract}

The structure of optimization model of optimal management of raw materials, fuel and energy resources in the blast-furnace shop of iron and steel works is represented. The following blocks are taken as system basis: (1) calculation of the set of parameters that characterize the thermal, gas-dynamic, slag and blasting modes for every blast furnaces of the shop during the base period; (2) calculation of linearized model coefficients (constants of transferring via different exposure pathways) individually for every blast furnace as well as properties of iron ore raw materials, fluxing

Corresponding Author:

Nikolay Spirin

n.a.spirin@urfu.ru

Received: 6 June 2018

Accepted: 15 June 2018

Published: 17 July 2018

Publishing services provided by Knowledge E

(c) Nikolay Spirin et al. This article is distributed under the terms of the

Attribution License, which permits unrestricted use and redistribution provided that the original author and source are credited.

Selection and Peer-review under the responsibility of the TIM'2018 Conference Committee. additions, blasting parameters, parameters of fuel-enriched blast influencing the technical-and-economic indices of separate furnaces performance, their thermal, gasdynamic and slag operation modes in the course of blast-furnace melting according to UrFU-MMT blast-furnace production model within the base period; (3) solution of tasks that consider the optimal allocation of raw materials, fuel and energy resources for the project period of blast furnaces operation; (4) analysis of obtained results and providing of recommendations on the optimization of blast furnaces parameters. The developed functional model of optimal distribution of raw materials, fuel and energy resources for the engineering and technology personnel of blast-furnace shop is illustrated; the main functions and interconnections between the separate functional blocks are defined. The functions of created 'Optimal management of raw materials, fuel and energy resources in the blast-furnace production' software that is realized in the Microsoft Visual Studio 2017 (C\# programming language) programming environment in the form of web application are pointed out. The program product provides the engineering and technology personnel of blast furnace shop of iron and steel works with the opportunity to solve the tasks of optimal distribution of fuel and energy resources (natural gas and oxygen consumption) within the group of blast furnaces in the different technological situations.

Keywords: blast-furnace production, resources distribution optimization, fuel and energy resources, raw material resources, functional modeling, decision support system, software development 


\section{Introduction}

To solve the tasks relating to the management of complex difficult and energyconsuming process units in the dry metallurgy, it is necessary to use the modern automated systems of optimal management of raw materials, fuel and energy resources. The blast furnace processing is given the special place in the set of technological operations directed at obtaining the metal products as it is the most resource-intensive, energy-consuming and difficult operation using up to $50 \%$ of fuel materials consumed by the iron industry.

The analysis of current state of blast furnaces complex management provides an opportunity to draw the conclusion that it is necessary to be concentrated on the solving of challenging applied research task to create the automated subsystem for the optimal management of raw materials, fuel and energy resources, as well as forecasting of blast furnaces complex operation under the conditions of change in raw materials and fuel market, instability of composition and quality of smelt iron ore raw materials. Such task is to be solved based on development and application of new methods and algorithms [1-5]. The mathematical models of technical processes and production [6-8] represent the intellectual core of such system.

\section{Model Structure}

The structure of optimization model of optimal raw materials, fuel and energy resources management within the blast-furnace shop is represented in Figure 1 and includes the following main blocks:

1. Calculation of the set of parameters that characterize the thermal, gas-dynamic, slag and blasting modes of every blast furnace within the shop during the base period. The parameters of blast furnace melting are evaluated with the help of balance model of blast-furnace process developed within the natural simulation approach that may be conventionally divided into two parts, that is, model of base state and prediction model [8-11]. The model of base (reference) state enables the evaluation of the state of every blast furnace and influence of input parameters on the thermal, gas-dynamic and slag modes of blast furnace melting with the use of all actually available information on parameters of burden material, fuelenriched blast, blast-furnace gas and melting products. The prediction model with reference to the results obtained with the help of base (reference) state model provides an opportunity to evaluate the indices of blast furnace melting when the 


\section{Model of UrFU-MMK blast-furnace production}

Calculation of the set of parameters that

characterize the thermal, gas-dynamic, slag and

blasting modes foe every blast furnace of the shop

during the base period

Calculation of influence coefficients of input parameters (blasting parameters, IORM composition and properties,

fluxing material consumption and properties, coke

composition and properties) due to the indices of

thermal, gas-dynamic, slag and blasting operation modes

in the course of blast-furnace melting

Assignment of operation conditions in the project period for the whole blast-furnace shop and for every separate blast furnace

Planned average consumption, chemical composition and properties of every burden component (IORM, fluxing material, coke)

Restriction of the blast-furnace shop mainly to intake (consumption) of the iron ore raw materials (steel pellet, agglomerate, ore additives), fluxing materials and coke; to consumption of natural gas and industrial oxygen, composition of smelt iron; to operational target

Technological restrictions to every blast furnace

Figure 1: Structure of optimization model of optimal raw materials, fuel and energy resources management in the blast-furnace shop.

melting conditions are changed. The operating results of blast furnace and blastfurnace shop at all are known according to the data of technical report of blast furnace shop. The UrFU-MMK software and 'Technical report of blast-furnace shop' subsystem are used for this purpose [9-11]. The total number of technical report indices comprises more than 300 units. 'Blast-furnace shop technologist WKS' program unit is used to calculate the set of parameters characterizing the thermal, gas-dynamic, slag and blasting modes of every blast furnace within the shop during the base period (for about 30 parameters for every blast furnace) $[9,11]$.

2. Calculation of linearized model coefficients. The influence coefficients (constants of transferring via different exposure pathways), in particular, the properties of iron ore raw materials, fluxing materials, blasting parameters, parameters of fuelenriched blast that influence the technical-and-economic indices of work of certain furnaces and their thermal, gas-dynamic and slag modes of blast-furnace 
melting under the base period conditions, are calculated for every blast furnace with the use of blast-furnace process model [10]. Considering the model linearity, these coefficients for given furnace are further regarded to be the constant ones in relation to the chosen base period when solving the prediction tasks. The probability of linearization of mathematical model of blast-furnace process are evaluated for the operating conditions of separate furnaces; the possible limits of raw materials, blasting and mode parameters change, as well as use of linear mathematical programming methods to solve the optimization tasks are determined. At the same time, the methods evaluating the blast-furnace process linearity that were developed earlier on and represented in the works $[9,11]$ are also used.

Thus, to improve the rating reliability, the model uses the incremental relations that allow bringing of task to the task of linear mathematical programming as well as excluding the influence of instrumentation and accuracy errors for information channels.

Furthermore, the tasks of optimal raw materials, fuel and energy resources distribution during the project period are solved. This includes the following blocks:

1. Setting of working conditions in the project period for the whole blast-furnace shop and every furnace in particular.

(a) The task of planned average consumption, chemical composition and properties of every burden component including the iron ore raw materials, fluxing materials and coke are executed. The general planned shop production is evaluated by means of the conversion model factor and reference data (technological instruction) acceptable for the operating conditions of blastfurnace shop at all; the production is distributed during the project period for every blast furnace. The consideration of technical condition for every blast furnace, their repair schedules and planned furnace shutdown is carried out by means of Delphi approach.

(b) Setting of restrictions of the blast-furnace shop mainly to intake (consumption) of iron ore raw materials (steel pellet, agglomerate, ore additives), fluxing materials and coke; to consumption of natural gas and industrial oxygen, composition of smelt iron; to operational target.

(c) Setting of technological restrictions to every blast furnace characterizing the thermal, gas-dynamic and slag modes of blast-furnace melting, composition and properties of found iron. 
2. Solution of task relating to the selection of optimal composition of blast furnace burden material under the operating conditions in the projection period for every separate unit. Solution of task that considers the optimal composition of blastfurnace burden material for every blast furnace at the set bypass ratio of agglomerate and steel pellet with the possible correcting of fluxing material and agglomerate basicity as well as consideration of limitations on the thermal, slag and gas-dynamic melting modes. At the same time, the following variants of tasks solution are provided in priority order:

3. Correcting of burden material composition by the bypass ratio of agglomerates/steel pellets if the fluxing additives are absent;

(a) Correcting of burden material composition only by means of fluxing additions consumption;

(b) Any combination of stated variants is possible.

4. Solution of task relating to the optimal distribution of natural gas throughout the blast furnaces under the operating conditions of project period:

(a) Formalization of restrictions to the thermal, gas-dynamic and slag operation modes of blast-furnace melting for every shop furnace;

(b) Formalization of general shop restrictions to the consumption of fuel and energy resources: consumption of natural gas, process oxygen, coke, as well as cast-iron production;

(c) Bypass ratio of natural gas and process oxygen is set due to the guard condition of maintenance of burning temperature on the injection lances at the scheduled interval.

(d) The objective function is set as the task to minimize the coke consumption.

5. Analysis of obtained results. The peculiarity to solve the complex optimization tasks of mathematical programming relates to the fact that there are possible cases when the limitations laid on the furnace operation modes are contradictory (there is no region of feasibility). Due to this, the solution algorithm provides the analysis stage for the task solution. In case of absent region of feasibility and conditions contradiction, it is required to apply the correcting stage (to evaluate the correct use of burden materials, restrictions, reliability of source information etc.). 


\section{Functional Modeling of Optimal Raw Materials and Energy Resources Distribution}

The method used for the development of functional model is based on the idea, notation of IDEFo (Integrated computer aided manufacturing DEFinition) structural analysis and designing methodology. The use of this methodology provided an opportunity to create the functional structure of program complex, find out the activities it performs as well as connections between these activities, controlling actions and execution mechanisms of every function

As a result, the functional model of optimal raw materials and energy resources distribution for engineering and technology personnel of blast-furnace shop is developed based on system approach; the main functions and interconnections between the separate functional units are determined. The total number of decomposed units of functional model embraces 115; the fragment is shown in Figure 2.

'Prepare the initial dato for calculation' function (A1) ensures the retrieval of necessary actual reporting indicators of blast furnaces operation characterizing the thermal, gas-dynamic, slag and blasting modes of every blast furnace within the shop during the base period from the database of blast-furnace production; the averaging of indicators for the user-defined period; setting of value characteristics of all types of fuel and energy resources; calculation of all coefficients of linear UrFU-MMK model due to the assessment of impact of input parameters (blasting parameters, composition and properties of IORM, fluxing materials consumption and properties, coke composition and properties) on the indices of thermal, gas-dynamic, slag and blasting operation modes of blast-furnace melting.

'Work out restrictions and perform calculations for base period' function (A2) ensures for the base period: formation of restrictions of the blast-furnace shop mainly to intake (consumption) of iron ore raw materials (steel pellet, agglomerate, ore additives), fluxing materials and coke, to consumption of natural gas and process oxygen, composition of smelt iron and operational target; formation of technological restrictions to every blast furnace (theoretical burning temperature; composite index of thermal condition of furnace bottom; ratio of heat capacities of shaft flows; degree of burden material compensation; slag properties (slag viscosity at different temperatures, viscosity gradients); sulfur and silicon content in iron; consumption of natural gas by blast furnaces; coke consumption by the furnace); calculation of optimization task for the base period. 


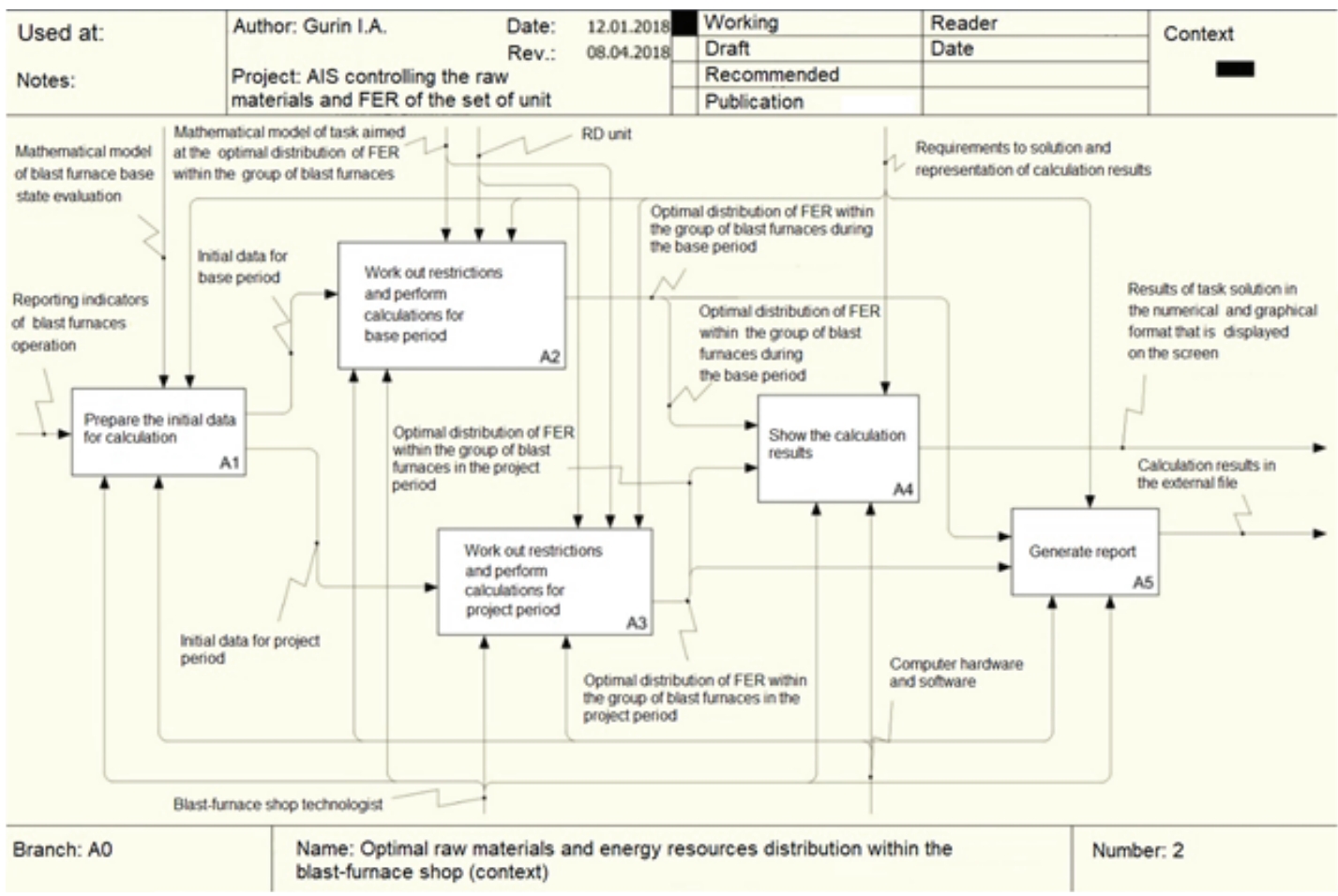

Figure 2: The first level of decomposition of functional model of optimal raw materials and energy resources distribution.

'Work out restrictions and perform calculations for project period' function ( $\mathrm{A}_{3}$ ) ensures the following settings in the project period: planned average consumption, chemical composition and properties of every burden component (IORM, fluxing materials, coke); formation of restrictions of the blast-furnace shop mainly to intake (consumption) of iron ore raw materials (steel pellet, agglomerate, ore additives), fluxing materials and coke, to consumption of natural gas and process oxygen, composition of smelt iron and operational target; technological restrictions to every blast furnace; calculation of optimization task for the project period.

'Show the calculation results' function ( $\mathrm{A}_{4}$ ) ensures the display of solved results of optimization task on the screen in the numerical and graphical format.

'Generate report' function (A5) provides an opportunity to prepare the list of indices for exporting to the external file of commonly used office documents formats (Word, Excel, CSV, PDF and others).

\section{Mathematical, Algorithmic and Information Support}

The structural system analysis and designing of mathematical model units are performed based on procedure-oriented approach. The basis of this approach consists in the use of DFD (Data Flow Diagrams) of information model the main components 
of which are represented by data flows that transfer information from one unit to another. The notation of DFD method suggests the partition of mathematical model on the separate functional components (processes) and their representation in the form of network connected with the data flows.

Blast furnace burden material optimal composition selection. The solution block chart for the task calculating the optimal composition of blast-furnace burden material is represented in Figure 3. The optimization model includes two main components: objective function and technological restrictions to every blast furnace.

Calculation of the optimal natural gas distribution. The optimal distribution of fuel and energy resources within the group of blast furnaces and, particularly, injected fuel and process oxygen within the group of blast furnaces is an actual task because the technological parameters of operation of separate furnaces differ considerably. It makes sense to have the strategic methodology to evaluate the efficiency of specified resources use for the blast furnaces as well as carry out their optimal distribution if having the set general consumption of these resources within the blast-furnace shop. Figure 4 shows the flow diagram solving the optimization task of fuel and energy resources distribution within the group of blast furnaces.

The following variants of objective functions are provided:

1. Minimal coke rate:

$$
\mathrm{Z}=\mathrm{K} \rightarrow \min _{X_{\mathrm{i}, \mathrm{B}} \in G_{x_{B}}}
$$

2. Maximal performance:

$$
\mathrm{Z}=\mathrm{D} \rightarrow \max _{X_{\mathrm{i}, \mathrm{B}} \in G_{x_{B}}},
$$

where i - type index of burden materials and fuel-energy resources; $X_{i, B}$ - vector characterizing the types, rate and chemical composition of i materials of blastfurnace burden, fuel and energy resources; $X_{i, \mathrm{~B}} \in G_{x_{\mathrm{B}}}$ - restriction on burden parameters, that is, types, chemical composition of fed burden materials, fuel and energy resources; $G_{x_{\mathrm{B}}}$ - region of feasibility of burden, fuel and energy resources parameters.

Formation of technological restrictions presupposes the accounting and mathematical description of restrictions to the thermal, gas-dynamic and slag melting modes.

The 'Optimal management of raw materials, fuel and energy resources during the blast furnace production' software in the form of web application is developed in accordance with the modern principles of application programs development (functionality, 


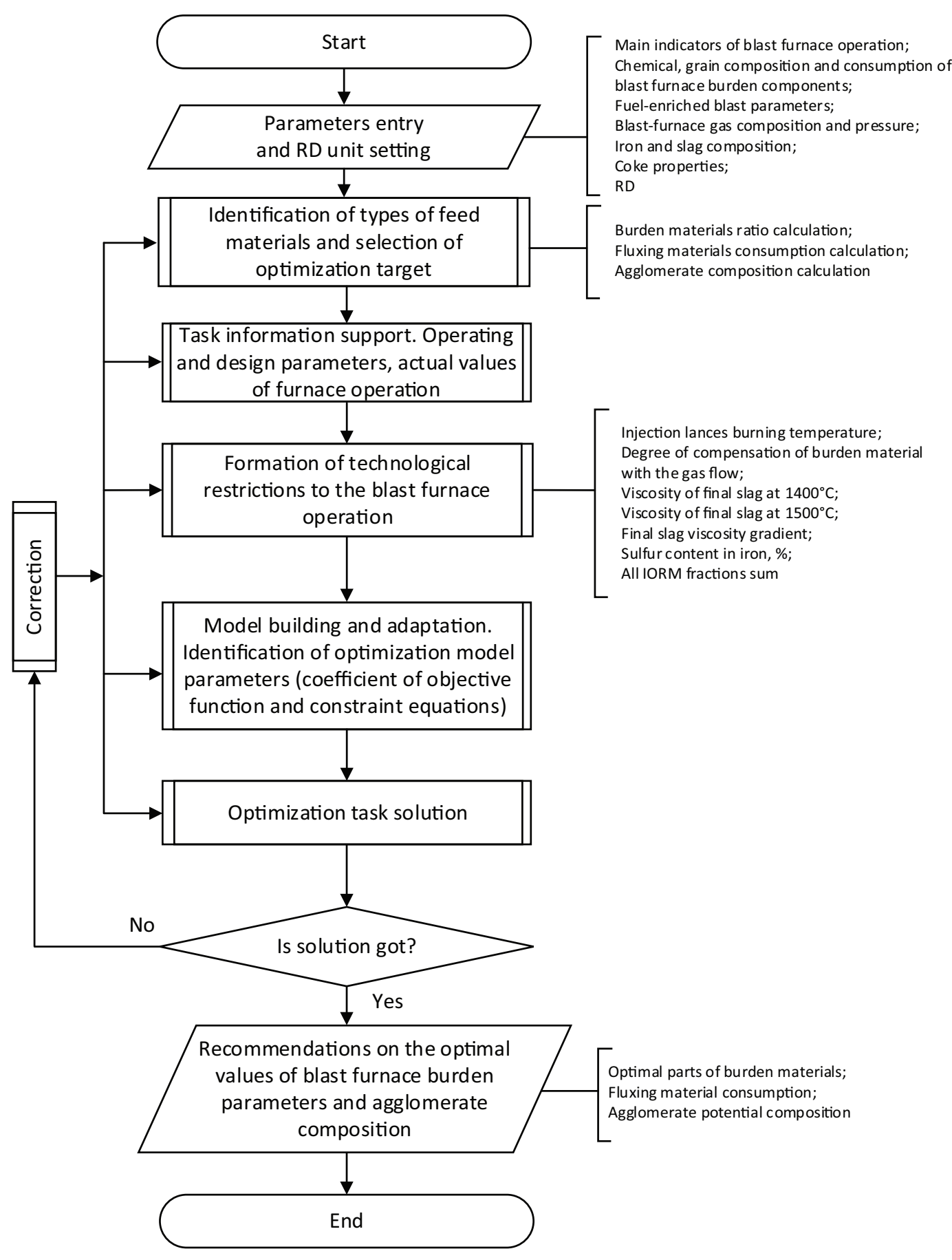

Figure 3: Solution sequence of task on calculating the optimal composition of blast-furnace burden.

expandability, integration with databases, user-friendly interface, safety, information estimation). NET technology is the basis for program implementation thus giving the additional freedom to choose the platform and programming language. The program product is written in C\# language with the use of Microsoft Visual Studio 2015 programming environment. 


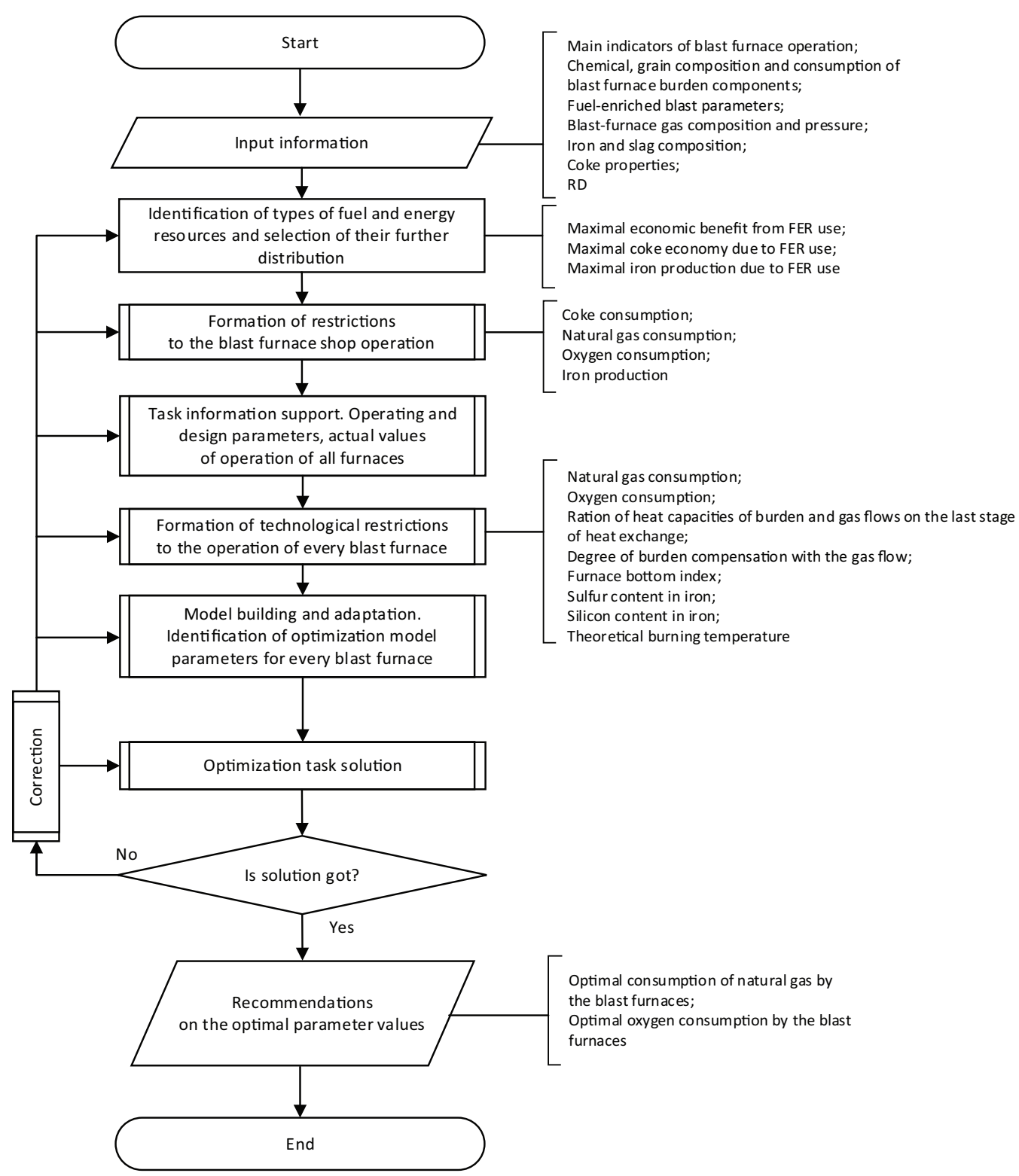

Figure 4: The block chart solving the task of optimization of fuel and energy resources distribution within the group of blast furnaces.

The software for choosing the blast furnace burden optimal composition provides the solution of the following technological tasks:

1. Selection of optimal ratio of agglomerate parts and one of types of imported steel pellets (the material that helps correct the burden to further obtain the necessary burden basicity is chosen from the dropdown list);

2. Selection of consumption of one of fluxing materials (the type of fluxing material that helps correct the burden to further obtain the necessary burden basicity is chosen from the dropdown list); 
3. Selection of agglomerate chemistry (basicity) during the project period at the set consumption as well as portions of iron ore and fluxing materials.

The subsystem software calculating the distribution of fuel and energy resources provides an opportunity to solve the tasks of optimal distribution of consumed natural gas and oxygen in the following technological situations:

1. If changing the volume of resources due to the consumption of natural gas and oxygen within the whole blast-furnace shop;

2. If determining the maximal volume of resources of fuel-enriched blast that may use the complex of blast furnaces;

3. If changing the resource by the volume of coke possessed by the blast-furnace shop;

4. If changing the requirements of assignment for the volume of the found iron by the complex of blast furnaces;

5. If changing the market conditions, that is, requirements ensuring the maximal coke economy, maximal production, economical performance of furnaces complex as well as prices of fuel and energy resources etc.

\section{Summary}

1. The functional model of optimal management system of raw materials, fuel and energy resources in the blast-furnace production is developed.

2. The following subsystems structures are realized:

3. Selection of optimal composition of blast-furnace burden that allows the determination of necessary ratio of burden materials, fluxing materials consumption and agglomerate composition that ensures its set basicity if considering the set technological restrictions to the slag, gas-dynamic and thermal operation modes of blast furnaces;

4. Selection of optimal distribution of fuel and energy resources within the group of blast furnaces in the different technological situations (maintenance or change of general consumption of natural gas, oxygen and coke for the blast-furnace shop at all; correction of operating and design parameters of furnaces included into the concerned group; change of market conditions) differing by the consideration of technological restrictions to the operation of separate furnaces. 
5. The complex of algorithms for optimal distribution of raw materials, fuel and energy resources between the furnaces of blast-furnace shop with consideration of technological restrictions in the conditions of unstable composition and quality of smelt iron ore raw materials and fuel as well as changeable market conditions is developed.

6. The proper software is developed with the help of modern technologies.

\section{References}

[1] Porzio, G. F., Colla, V., Matarese, N., et al. (2014). Process integration in energy and carbon intensive industries: An example of exploitation of optimization techniques and decision support. Applied Thermal Engineering, vol. 70, no. 2, pp. 1148-1155.

[2] Bandyopadhyay, S. and Sahu, G. C. (2011). Minimization of resource requirement and inter-plant cross flow across resource allocation networks. Chemical Engineering Transactions, vol. 25, pp. 279-284.

[3] Froehling, M., Schwaderer, F., Bartusch, H., et al. (2010). Integrated planning of transportation and recycling for multiple plants based on process simulation. European Journal of Operational Research, vol. 207, no. 2, pp. 958-970.

[4] Ganjehkaviri, A., Mohd Jaafar, M. N., Ahmadi, P., et al. (2014). Modelling and optimization of combined cycle power plant based on exergoeconomic and environmental analyses. Applied Thermal Engineering, vol. 67, no. 1-2, pp. 566-578.

[5] Martin, E., Meis, M., Mourenza, C., et al. (2012). Fast solution of direct and inverse design problems concerning furnace operation conditions in steel industry. Applied Thermal Engineering, vol. 47, pp. 41-53.

[6] Kuang, S., Li, Z., and Yu, A. (2018). Review on modeling and simulation of blast furnace. Steel Research International, vol. 89, no. 1, Code UNSP 1700071.

[7] Ariyama, T., Natsui, S., Kon, T., et al. (2014). Recent progress on advanced blast furnace mathematical models based on discrete method. ISIJ International, vol. 54, no. 7, pp. 1457-1471.

[8] Spirin, N. A., Lavrov, V. V., Yu, V., et al. (2011). Model Systems of Decision Support in CAPCS of Metallurgical Blast-furnace Melting, N. A. Spirin (ed.), p. 462. Yekaterinburg: UrFU.

[9] Spirin, N. A., Lavrov, V. V., Burykin, A. A., et al. (2011). Complex of model systems for supporting decisions made in managing blast-furnace smelting technology. Metallurgist, vol. 54, no. 9-10, pp. 566-569. 
[10] Spirin, N., Gileva, L., Lavrov, V., et al. (2015). The pilot expert system to control blast furnace operation. AISTech 2015 Iron and Steel Technology Conference and 7th International Conference on the Science and Technology of Ironmaking, ICSTI 2015. Cleveland, United States,. Code 113707, vol. 1, pp. 1225-1232.

[11] Spirin, N. A., Lavrov, V. V., Rybolovlev, V. Y., et al. (2016). Use of contemporary information technology for analyzing the blast furnace process. Metallurgist, vol. 60, no. 5-6, pp. 471-477. 